\title{
A COMPARATIVE STUdy E-COMMERCE DeVElopMENT METHOD: AdAPTING AN AgILE APPROACH IN MOBILE OCCASION E - COMMERCE SYSTEM
}

\author{
Beshair Khalid Alsiddiq and Nor Shahida Mohd Jamail \\ Collage of Computer and Information Science, Prince Sultan University, \\ Riyadh, Saudi Arabia
}

\begin{abstract}
E-commerce nowadays has expanded in the past years, and it is substituting the traditional brick and mortar stores. And most of the brands now have their own web or mobile application so the users can shop online, it is easier and faster. Building an e-commerce application is like any other software it goes through phases in the SDLC. This paper is going to be a guide to adapt the Agile mythology in the development of the mobile e-commerce application.
\end{abstract}

\section{KEYWORDS}

E-commerce, Agile, E-commerce application.

\section{INTRODUCTION}

In recent times, with the rising ability of the mobile e-commerce market, specialists are looking for increasingly adaptable strategies that can be utilized to conform to dynamic condition where the mobile e-commerce framework condition are changing after some time. The agile strategy encourages the software developing processes to accept the new changes at any phase of the project, clients are dealt with independently as associates and unpreventable developmental changes can be recognized. Agile methodologies construct a hugely collaborative to the software improvement.[1] Normally, it's connects with the 'lean' practice, agile software advancement intently pursues into stream of the business esteem, including the attention to the exercises that straightforwardly adds the task true objective of the software's quality. The Agile manifesto distributes the characterize methodology, it is currently known as the agile software development process and the guiding force for Agile users.

Agile methodologies appeared to suit changing business requirements and for better administration of the software improvement lifecycle.It gives rehearses that encourage correspondence between the engineer and the client, and undergo develop-deliver feedback cycles, to have increasingly explicit perspective on the requirements, and be prepared for any change whenever.Agile development methodology enables organizations to build the correct item and engages groups to consistently upgrade their release to optimize its value all through advancement, enabling them to be as competitive as conceivable in themarketplace. $[7,8]$ Subsequently, the fundamental point of the approach is to convey what is required at a suitable time during the advancement cycle. Agile methodologies are among the best programming advancement ways to deal with apply now and again, when the client's requirements are not 
correct, or when the due dates and spending plans are tight. However, other than the advantages related in utilizing agile advancements in mobile software development, there are issues that brings up concerns in detailing gains in quality, profitability and business fulfillment by various groups. It has been accounted for that agile strategies had been effective in conveying for themajority parts of cases, there are clashing reports that guarantee that the approach is still too young to even think about requiring extensive academic proof of their success of their prosperity. This paper is an attempt to survey the distributed literature on the utilization of the agile methodologies for the improvement of mobilesoftware as the specialists trust that agile innovations offer an answer for portable explicit applications that require excellent advancement processes.[9]

\section{LITERATURE REVIEW}

Agile development is a methodology depends mostly on producing a high-quality product in less time, small groups and also less documenting. Researchers and experts have shown that agile is suitable for all kind of systems especially for the small projects.

Abrahamsson et al. [3] declared the features of the agile technologies that suits in mobile software development and why it is suitable. The different conflicts include, environment dispersal, few members in the development team, known customer, small systems and short development

cycles. Harleen K. Flora ${ }^{1}$, Dr. Swati V. Chande. [1] noted that agile methodology is the most suitable fit for the mobile application developments process. Also, most of the studies for the application of the techniques that agile development contains to the mobile application development indicates the need for software development processes tailored to suite the mobile application requirements.Srinivasan J, Dobrin R, Lundqvist K. [4] illustrated that agile techniques hold a great promising to decrease the cycle times and also providing a greater worth to the all key that the stakeholders involved in the software ecosystem. While these methods seem to be very suitable for the embedded systems development process, the uses have not become a very widespread practice.

\section{E - COMMERCE:}

In the 1970s was the first online transaction. The action was made using the ARPANET (early packet-switching network). Students at Stanford University and the Massachusetts Institute of Technology (MIT) made the deal quietly because it was an illegal drug deal [2]. That's was the start of the e-commerce. E-commerce is an online business when the user can purchase or sell an item by electronic methods, it's indicated to both online retail and electronic transactions.

\section{MOBILE E - COMMERCE APPLICATION:}

Kevin Duffy started the expression of the m - commerce in 1997 at the launch of the Global Mobile Commerce Forum, to be a sign of "the conveyance of electronic business capacities" precisely to the customers hand, and anywhere, by the wireless technologies. The mobile ecommerce application will be developed through the SDLC stages (Software Development Life Cycle), which are:

1. Planning and analyzing.

2. Designing.

3. The Implementation.

4. Testing the system.

5. The Maintenance. 
SDLC can hail errors in software invention before they can be found (which will cost a lot greater expense) in advanced stages. Although, it is extremely more than that, the Software Development Life Cycle can spread out a configuration to get everything right and at time the first run through.

Agile development is one of the newest and fastest mythology of the software development life cycle, it launches the product fast and contiguously updates it to a better application.

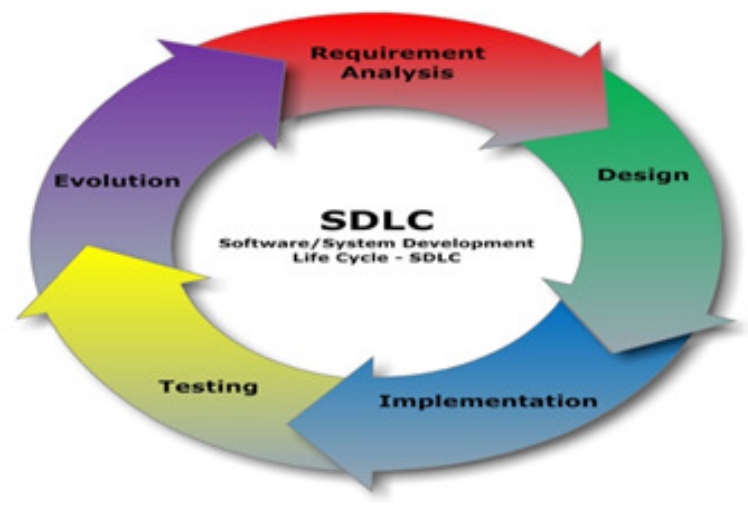

Figure 1. Software Development Life Cycle.

\section{E-COMMERCE OCCASION SYSTEM}

The motivation behind this research is to investigate a portion of the issues confronted when starting to think about doing events and occasions that could impact the last outcomes began with organizing the event and money related expense. Following the approaching gatherings and occasions help to abstain from clashing in future occasions. Event planning is the way toward arranging a festival, celebration, party or pretty much any occasions. It incorporates planning, choosing the dates and setting.

With the assistance of social media, it empowers to design an occasion better. Events are recreation activities and work possibilities for people." Events unite people together to have great time and make delightful memories. They enhance the quality of people's life due to the fact of providing a significant economic and providing a revenue for special projects. Hillary Commission for Sport, (1997) said, notwithstanding size, occasions require a high level of arranging, a scope of abilities and a ton of energy.

FourSquare (a geolocation stage) is a location-based social networking application, for mobile devices. Clients "check-in" at scenes utilizing a portable site, text messaging or a gadget explicit application. The occasion coordinators have worked together with Foursquare to make another experience like winning an identification to get access to an after-party, this is extremely a proficient method to make the occasion livelier and intuitiveness between visitors appears to be a lot less demanding and smoother. For example, the occasion by Ralph Lauren Big Pony Fragrance Dinner.

According to Andersson and Wesslau (2000), when utilizing occasions, organizations to get the possibility to have their own-right to the consumer during the duration of the event. This implies if an organization figures out how to motivate the customer to go to the occasion, the contortion from the competitors will be gone or if nothing else limited amid the span of the occasion.

Additionally, occasions contain substantial components, for example, nourishment, refreshments and different items sold or given away, however are basically an administration in that they comprise of immaterial encounters of limited length inside an impermanent, oversaw climate. 
Similarly, as with all administrations, this experiential "item" is delivered and expended at the same time, is exceptionally heterogeneous and extremely hard to store or control.

In other hand, OpenSooq is an application that only covers the Middle East and North Africa region. With more than a quarter of a billion hits per month, monthly traffic is growing, making it one of the leading online markets in the Middle East and North Africa. But this huge platform not focus on events and party's planner it only an e-commerce platform for different goods. The open now is a part of the iMENA Group in 2012. The open sooq enables vendors to deliver their products and services online to millions of users without an intermediary, while visitors can easily browse thousands of goods, products and services covering different categories; real estate, automobiles, electronics, Work and many more. The application gives users the same functionality they can see on the site, and can browse and publish ads to buy, sell or rent all types of products and services, as well as advertise or even apply for vacancies. But now days we need an urgent to tools that focus on events and party's planner that organize and plan our events to make our life easier and more flexible.

\section{AgILe ApProACH}

Agile software development is an approach of programming, the enhancements of the software going to be under the requirements and the arrangements that will be developed over the mutual effort of self-sorting out and cross-utilitarian groups and their customer(s)/end user(s). It advocates many - sided arranging, transformative advancement, experimental learning, and constant enhancement, and also it empowers quick and flexible reaction to the change.Agile spread-out, by the Manifesto for Agile Software Development. Due to great qualities and standards which embrace in the manifesto are supported in a wide scope of programming advancement structures, including Scrum and Kanban. There is considerable anecdotal evidence that adapting agile methods and qualities will improve the lightness of software experts, groups and associations; in any case, some exact examinations have discovered no logical proof.The Agile Manifesto set up a typical arrangement of larger qualities and standards for the majority of the individual agile approaches. Its subtleties the main four fundamental beliefs for empowering high-performance, efficiency, and outputs which are:

- Individuals and communications.

- Establishing a functional software.

- The customer's cooperation.

- reacting to change.

Those four important qualities are upheld by 12 standards which underlie the Agile Manifesto:

1. The Satisfaction of the Customer.

2. Welcoming changing requirements.

3. Short time of the delivery cycle.

4. The cooperation among business people and developers.

5. A motivational atmosphere between team members.

6. Face confronting correspondence.

7. A functional software-Primary measure of progress.

8. Agile promoting sustainable development.

9. Continuous attention regarding technical excellence and good design.

10. Simplicity.

11. Self-Organization to have the best outcomes.

12. Self-improvement. 


\section{THE AGILE SDLC:}

Underneath Agile SDLC looks similar to the classic Software Development Life Cycle, however, when plunged further, it is not the situation due to the fact that the agile Software Development Life Cycle is hugely cooperative, iterative, and step - by - step to the jobs which individuals take considerably more vigorous than on classic project.

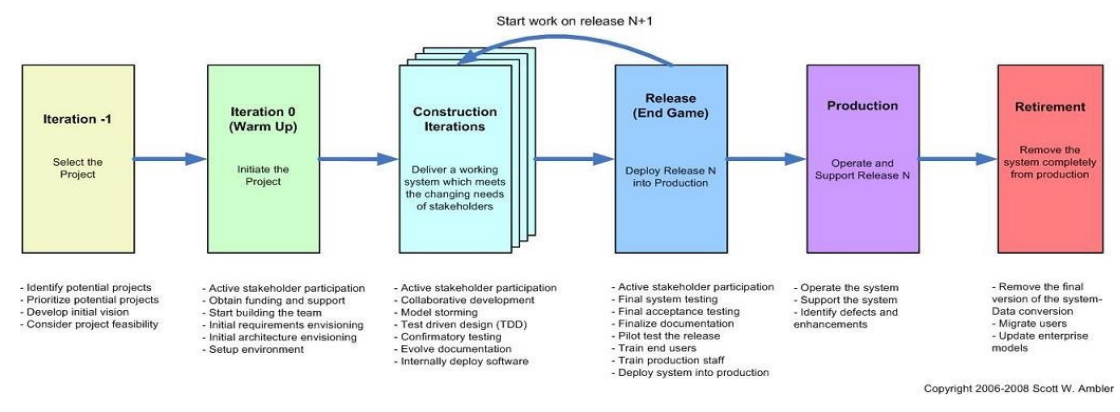

Figure 2. Agile SDLC

\section{TECHNIQUES:}

A portion of the most outstanding agile software development techniques:

\section{Extreme Programming $(X P)$ :}

The main purposes are to improve the software's quality and responsiveness to changing customer requirements. As a kind of agile progress, it advocates visit "deliveries" in a short time of improvement cycles, which is intended to upgrade efficiency and present checkpoints at which new customer requirements can be embraced.

\section{Scrum:}

It is about managing knowledge work, with an assurance on the new improvement of the software. It was created for small teams that are consist of three to nine members, they will divide their tasks to a number of activities which will be done inside the timeboxed iterations, called " sprints ", and these activities will not exceed one month to be done and most usually couple of weeks to finish these activities, at that point tracking the progress and then planning again in 15-minute stand-up gatherings, called day by day scrums.

\section{Agile Modeling (AM):}

Agile Modeling (AM), is a training - based methodology for modeling and documentation of software-based systems. It is expected to be an accumulation of qualities, principles, and practices for displaying software that can be adapted on a software development project in a more adaptable way than conventional demonstrating strategies.

\section{Crystal:}

It focuses on individuals and the communication among them while they work on a software development project. There is additional attention on business-criticality and business-need of the framework under development. Unlike traditional development methods, Crystal doesn't fix the apparatuses and systems of development, however, it keeps individuals 
and processes at the center of the improvement processes. Also, it isn't just the people or the processes that are matters, rather the communication between the two that is what matters the most.

\section{Dynamic Systems Development Method (DSDM):}

Rather than settling measures of functionality in an item, afterward changing time and assets that will achieve the functionality, will be better to fix the time and resources, then afterward modifying all measure of functionality appropriately.

\section{Adaptive Software Development (ASD):}

It combines the rules of the continuous adoption of the system to the current performance situation. Adaptive software development substitutes the traditional waterfall cycle with a duplicating series of speculating, team up, and learn cycles. This dynamic cycle accommodates nonstop learning and adjustment to the new condition of the project.

\section{Feature-Driven Development $(F D D)$ :}

The main focus is the designing and building stages and the priority is the quality viewpoints all through the whole progress and incorporates repeated and sensible deliveries, alongside with careful observation of the project's process.

\section{Internet-Speed Development (ISD):}

Addresses the issue of taking care of quick release for the development cycles in very short time. Also, the structure made up of time drivers, quality conditions and process changes.

\section{Agile Adaptation In E-COMMERCE}

Each mobile e - commerce application has its own challenges depending on its unique features. And most of the e-commerce applications developers follows the traditional development process to make sure that the project has been developed in time, in budget and to achieve the application's requirements and needs. Here is the development life cycle of a mobile application:

1. Concept/ Scope.

2. Requirement Analysis.

3. Planning.

4. Design preparation.

5. Development.

6. Testing.

7. Final Delivery.

8. Maintenance.

Each step has a very suitable agile technique to provide a better product that will be delivered in time for the costumers and on budget for the organization, because agile is about short time, flexibility in the development cycle which responses fast to the customer's needs. Also, it is a continuous building a two - way software pipeline between the organization and its customer. The process of the software will be a continuous delivery and updating the software from the start. 


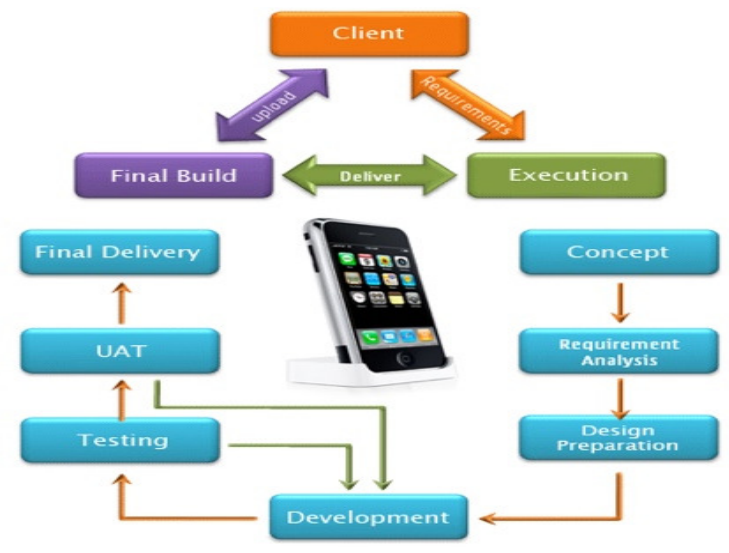

Figure 3: Mobile application Life Cycle.

Table 1.

\begin{tabular}{|c|c|c|}
\hline Phase & $\begin{array}{c}\text { Suitable } \\
\text { Agile } \\
\text { Technique }\end{array}$ & Reason \\
\hline Concept / Scope. & Scrum & $\begin{array}{l}\text { Focuses on managing the project and } \\
\text { improving the software to deliver in } \\
\text { time with best quality. }\end{array}$ \\
\hline Requirement Analysis. & $\mathrm{XP}$ & $\begin{array}{l}\text { Focuses on the requirements, the XP } \\
\text { technique adapts and accepts all of the } \\
\text { changing requirements at any time and } \\
\text { stage. }\end{array}$ \\
\hline Planning. & Scrum / XP & $\begin{array}{l}\text { The main focuses in this phase is the } \\
\text { requirements and the software itself as } \\
\text { well. The requirements might change } \\
\text { so the XP will accept it and adapts to } \\
\text { the system, with changing } \\
\text { requirements maybe change the } \\
\text { software might occurs as well, so } \\
\text { Scrum will manage the software } \\
\text { changes and also projects managing. }\end{array}$ \\
\hline Designing/Preparation. & Scrum & $\begin{array}{c}\text { To managing the project properly and } \\
\text { to improve the software as well, to } \\
\text { deliver the best quality of the } \\
\text { software. }\end{array}$ \\
\hline Development/Testing. & $\mathrm{XP}$ & $\begin{array}{l}\text { XP accepts any chang es, so the } \\
\text { development phase it may occurs } \\
\text { some changes wither it was in the } \\
\text { requirements or changes in the } \\
\text { software. }\end{array}$ \\
\hline Final Delivery. & Scrum & Managing the project/system. \\
\hline Maintenance. & $\mathrm{XP}$ & Changes might occur. \\
\hline
\end{tabular}


International Journal of Computer Science \& Information Technology (IJCSIT) Vol 11, No 4, August 2019

\section{DIAGRAM:}

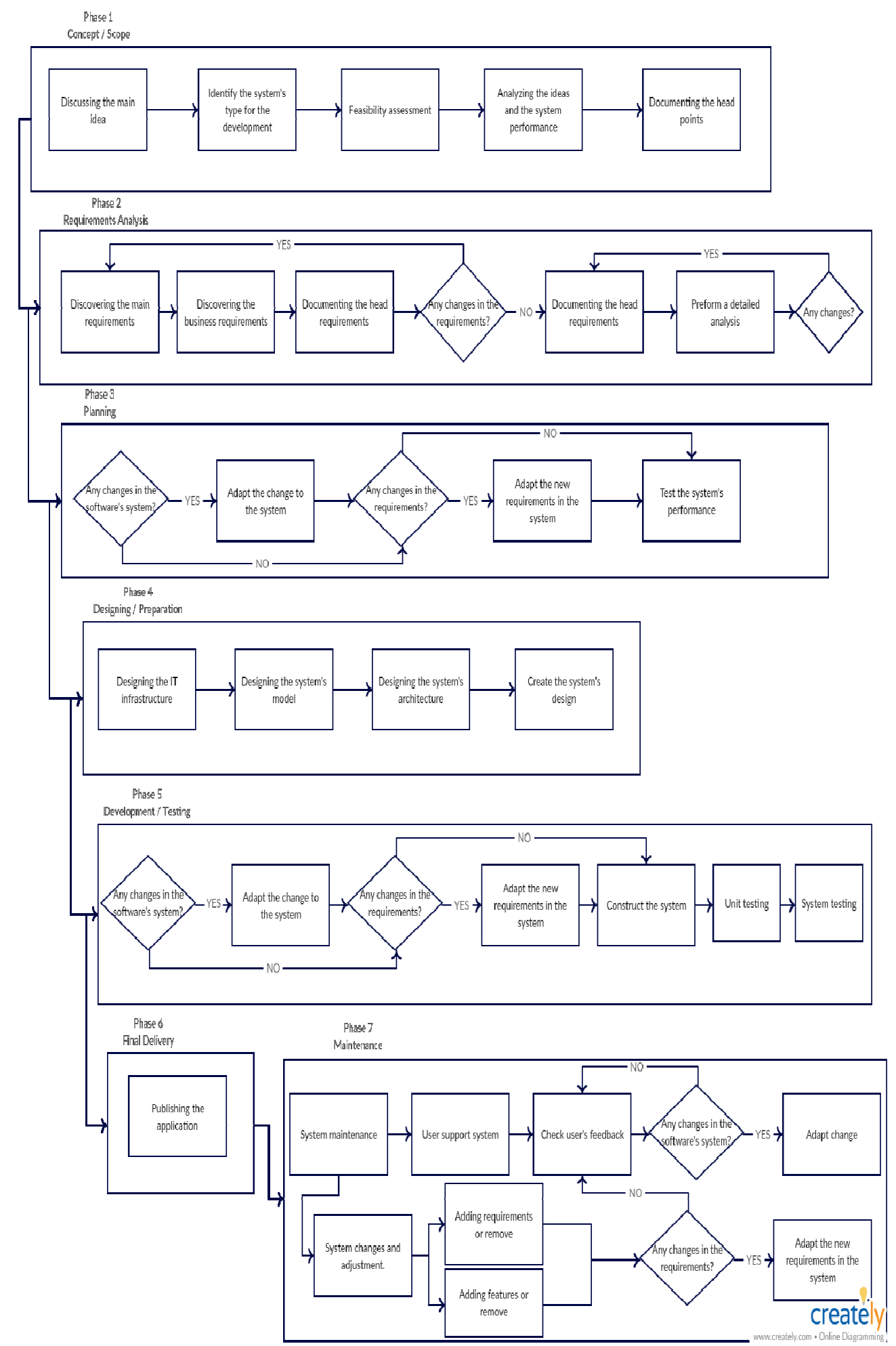

Figure 4: Diagram for Agile Mobile Application 


\section{Conclusion}

Choosing the best software methodology for the mobile e-commerce application is not hard nor easy. There is no only one suitable model for all the projects, planning requirements and also the payment model, but agile methodology especially for the small businesses will hugely help the most, due to its fucose on the project and the customer's needs and satisfaction as well in the same time. These small businesses that does not have a huge data it suits the best for agile because there is less documentation and publishing a product in short time. And for the ecommerce applications and e-commerce businesses in general as well their main focus is satisfying the customer, publishing a system in a short amount of time and providing a highquality product. Also, agile methodology has multiple techniques which were introduce above that can suites most of the projects.

\section{ACKNOWLEDGEMENTS}

We would like to acknowledge the Artificial Intelligence and Data Analytics (AIDA) Lab, Prince Sultan University, Riyadh, Saudi Arabia for supporting this work.

\section{REFERENCES}

[1] Harleen K. Flora, Dr. Swati V. Chande, "A Review and Analysis on Mobile Application Development Processes using Agile Methodologies ". International Journal of Research in Computer Science, 3 (4): pp. 9-18, July 2013. doi: 10.7815/ijorcs.34.2013.068.

[2] Knibbs, K. (2015, April 6). Remember How the First Thing Ever Sold Online Was a Baggie of Weed?

[3] P. Abrahamsson, "Keynote: Mobile software development - the business opportunity of today", Proceedings of the International Conference on Software Development, Reykjavik, Iceland, pp. 2023, 2005.

[4] Srinivasan J, Dobrin R, Lundqvist K. 'State of the Art' in Using Agile Methods for Embedded Systems Development. Mälardalen University.

[5] Flora, K. H. ADOPTING AN AGILE APPROACH FOR THE DEVELOPMENT OF MOBILE APPLICATIONS.International School of Informatics and Management. July 2012.

[6] Stamelos. I, Sfetsos, P. (2007). “Agile Software Development Quality Assurance”. 978-1-59904216-9, IDEA GROUP PUBLISHING

[7] “Manifesto for Agile Software Development”. Agile Alliance, 2001.

[8] A.I. Wasserman, "Software Engineering Issues or Mobile Application Development," Proceedings of the FSE/SDP workshop on Future of Software Engineering Research, FoSER '10, 397-400. doi: $10.1145 / 1882362.1882443$

[9] R. Holler, "Mobile Application Development: A Natural Fit with Agile Methodologies". VersionOne, LLC. 


\section{Authors}

Beshair Alsiddiq is a Software Engineering students in Prince Sultan University. She really committed in research and her interest are in Software Engineering, Cloud Computing and Mobile Development.

Dr. Nor Shahida Mohd Jamail is currently in Prince Sultan University, Riyadh, Saudi Arabia as an Assistant Professor. She obtained her PHD in Software Engineering from Universiti Putra Malaysia. Her specialized are purely in Software Engineering, Software Process Modelling, Software Testing and Cloud Computing Services. She had involved in Machine Learning Research Group in Prince Sultan University and also involved in 3 big research project which collaborated with Sultan Idris Educational University. Besides, she is the co-Chair, Track Chair, Committee in several

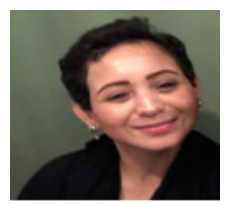

International Conference published by IEEE, Scopus indexed. Her current research interests are on Cloud Computing, Quality in Software Engineering and Software Modelling, Big data, Machine Learning and more on commercialization of research products. She can be contacted at njamail@psu.edu.sa 